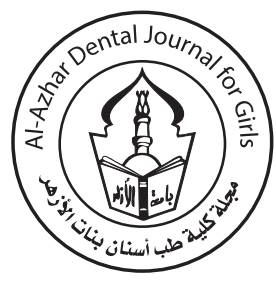

\title{
Evaluation of Laser Assisted Ridge Preservation Combined with Platelet Rich Fibrin and /or Bone
}

\author{
Rehab A. Osman ${ }^{1 *}$, Naglaa S. Elkilani ${ }^{2}$, Heba A. Adawy ${ }^{3}$, Mai S. Attia ${ }^{4}$.
}

Codex : 15/22.01

azhardentj@azhar.edu.eg

http://adjg.journals.ekb.eg

DOI: $10.21608 /$ adjg.2021.76197.1382

Oral Medicine \& Surgical Sciences (Oral Medicine, Oral \& Maxillofacial Surgery, Oral Pathology, Oral Biology)

\section{KEYWORDS}

Laser, platelet rich fibrin,

bone graft

\begin{abstract}
Purpose: The main target of our split mouth randomized controlled clinical trial was to evaluate how well laser assisted ridge preservation worked in conjunction with platelet rich fibrin (PRF) and/or bone clinical and radiographically. Subjects and Methods: Thirty extraction sockets from ten patients were split into three groups at random; group I treated by PRF and bone graft after atraumatic extraction, group II (PRF and laser assisted socket preservation) and group III (PRF, bone graft and laser assisted socket preservation). Width and height of the alveolar ridge observed at baseline, three and six months after treatment. Bone density recorded at six months after treatment using cone beam computer tomography (CBCT). Results: The mean ridge width in Groups II and III was statistically significantly higher than in Group I. After three and six months, there was no statistically significant difference between the three groups in ridge height. Group II had a higher mean of bone density. Conclusion: Within the scope of this research, laser-assisted ridge preservation appears to have better clinical and radiographic outcomes following tooth extraction.
\end{abstract}

\section{INTRODUCTION}

Presence of teeth is essential not only for functional demands but also for the esthetics of every individual. One of the most common procedures performed in dental offices is tooth extraction. Extraction can be due to caries, fractures, failure of endodontic treatment,

* Paper extracted from Doctor Thesis titled "Evaluation of Laser Assisted Ridge Preservation Combined with Platelet Rich Fibrin and Bone"

1. Assistant lecturer, Faculty of Oral and Dental Medicine, Al Fayoum University, Egypt.

2. Professor and head of Oral Medicine, Periodontology, Oral Diagnosis and Radiology, Faculty of Dental Medicine for Girls, Al-Azhar University, Cairo, Egypt.

3. Professor and head of Oral Biology Department, Faculty of Dental Medicine for Girls, Al-Azhar University, Cairo, Egypt.

4. Associate Professor of Oral Medicine, Periodontology, Oral Diagnosis and Radiology, Faculty of Dental Medicine for Girls, Al-Azhar University, Misr International University, Cairo, Egypt.

* Corresponding author email: dentroro84@gmail.com 
periodontal diseases or even the involvement of that tooth in pathologic lesions ${ }^{(1)}$. The healing process is important to restore the tissue integrity, also it is essential as defense response to maintain vitality and continuity of the organism. This process is a normal biochemical, mechanical, cellular and molecular response of the body. Healing in extracted socket is a specialized example of healing by secondary intention $^{(2)}$.

The bond between the reactor activators of nuclear kapa-b ligand (RANKL) in preosteoclasts and the reactor activator of nuclear kapa-B (RANK) began the process of alveolar bone resorption. Hence RANKL/RANK can be considered as the key regulation in the osteoclastogenesis process. This bond will stimulate (tumor necrosis factor). After that, TNF receptor-associated factor 6 (TRAF6), NF-B, c-Jun N-terminal kinase (JNK)/cJun/fos, and nuclear factor of activated T cells (NFAT) begin to differentiate precursor osteoclasts into preosteclast cells. About 1-4 weeks needed for resorption to take place by osteoclast mediation process ${ }^{(3)}$.

After extraction of the tooth the ridge undergoes resorption and remodeling of the alveolar crest. For an average of $0.7-1.5 \mathrm{~mm}$ of vertical and 4.0-4.5 $\mathrm{mm}$ of horizontal bone resorption, significant variations in the alveolar ridge width and height occur. The majority of these dimensional changes occur three months after extraction ${ }^{(4)}$. Hence preservation of alveolar ridge after extraction prior to implant placement is essential to maintain both hard and soft tissue are needed in the future for functional and esthetic needs ${ }^{(5)}$.

Several products, like allograft, xenograft, and alloplastic materials, as well as autogenous bone, resorbable or nonresorbable membranes made from different materials, and platelet rich fibrin (PRF), have been used to preserve the ridge after tooth extraction $^{(6)}$. Xenograft has many benefits over other products, including a slow rate of resorption, superior handling characteristics, promotion of revascularization and clot stabilization, and optimum integration with the patient's own bone. Xenograft contains similar hydroxyapatite content to that of nature bone, which allows the graft to revascularize and be replaced by new bone. For those reasons, xenograft is considered the most to be used in regenerative therapy for alveolar ridge preservation $^{(7)}$.

In alveolar ridge preservation, bone graft is inserted in the socket immediately after extraction of the tooth. Then a biocompatible membrane is applied to cover the bone graft that is subsequently covered by gum tissue. Both the graft and membrane trigger the body ability of healing. Regenerative techniques aid in the creation of new bone through osteoconduction, and osteogenic cells keep unwanted cells out of the wound, preserving the socket room ${ }^{(8)}$.

The availability of abundant growth factors is a crucial necessity for optimal and rapid wound healing, for fast healing of any wound abundant growth factors are required. PRF is the second generation of platelet concentrates, it is a convenient and inexpensive planning that saves time, it has the ability to facilitate both soft and hard tissue healing and regeneration, it can be used to treat intrabony defects, maxillary sinus augmentation, dental implants, gingival recession, furcation therapy, and the protection of the alveolar ridge ${ }^{(9)}$.

Erbium, chromium: yttrium-scandium-galliumgarnet (Er,Cr:YSGG) lasers have a wavelength of $2.78 \mathrm{~m}$ and can produce up to 6.5 watts of power. The high power is enough to remove hard tissue as tooth structure, the lower power setting is ideal for soft tissue cutting and coagulation. Since the Er,Cr:YSGG wavelength is highly absorbed by water, when the laser is aimed at biological tissues, the water inside the hard or soft tissues quickly heats up and transforms to steam, causing ablation of the tissue surface to a depth proportional to the laser wavelength and the tissue's water content. Er,Cr:YSGG have bactericidal effects and stimulate new bone formation in the furcation area in 
experimental periodontitis; hence it can be used in laser assisted ridge preservation after extraction ${ }^{(10)}$.

Low-level laser therapy (LLLT) using a diode laser has become common as a way to speed up wound healing. Its mechanism of action is based on the biostimulation or photobiomodulation theory. It has a biostimulatory effect because of its nonthermal effect, which helps to change cellular behaviour. It acts on the mitochondrial respiratory chain or membrane calcium channels to induce cellular changes. This intervention aids in the acceleration of wound healing by encouraging cellular metabolism and cell proliferation. In the other hand LLLT have an immediate analgesic effect ${ }^{(11)}$.

As a cross-sectional imaging modality of choice, CBCT has been positioned as an application with clear implications for implant therapy. When compared to other volumetric imaging modalities for the evaluation of mineralized tissues, CBCT is a radiographic instrument with greater accuracy, higher resolution, lower radiation exposure, and lower cost for patients. CBCT's three-dimensional (3D) knowledge can also contribute to better diagnostic understanding and treatment recommendations. Routine or inappropriate use of CBCT, on the other hand, would result in a significant increase in effective and cumulative patient radiation doses, which might not be justified in all situations ${ }^{(12)}$.

\section{SUBJECTS AND METHODS}

\section{Study design}

This was a split mouth randomized clinical trial with 30 defects that included in 10 patients $(7 \mathrm{fe}-$ males, 3 males). The participants age ranged from 30 to 50 years old, each patient have at least 3 teeth were indicated for extraction as caries non-restorable teeth, hopeless periodontally affected teeth and tooth with failure of endodontic treatment. All selected patients were systematically free. Smoker patients, pregnant and lactating women were excluded from our study. Patients were chosen from the De- partment of Oral Medicine and Periodontology, Diagnosis and Radiology, Faculty of Dental Medicine for Girls at Al-Azhar University in Egypt's clinic.

\section{Sample Size:}

The sample size of 30 defects (10 defects in each group) was adequate to detect the difference, according to sample size calculations ${ }^{(13)}$. A computer-generated table was used to distribute sites into three groups in a random and fair manner:

Group 1(GP1): included ten teeth indicated for extraction. Socket preservation procedures were done using PRF and bone graft.

Group 2(GP2): included ten teeth indicated for extraction. Socket preservation procedures were done using PRF and laser application.

Group 3(GP3): included ten teeth indicated for extraction. Socket preservation procedures were done using PRF, bone graft and laser application.

\section{Surgical procedures:}

Approval number (REC18-067) from Research Ethical Committee of Faculty of Dental Medicine for Girls, Al-Azhar University was received. Before surgery, the nature of the procedure was clarified to each patient, and each participant signed an informed consent document.

Before the surgery acrylic stent was prefabricated using radio-opaque wire in 6 points for each tooth to relocate the location of the extracted tooth in 6 months postoperative CBCT. The 6 points was Mesio buccal line angle (L1), Mid buccal (L2), Disto buccal line angle (L3), Mesio lingual line (L4), Mid lingual (L5), Disto lingual line angle (L6).

The patients were anesthetized using infiltration technique and/ or nerve block (Articaine 4\%, Spain) according to selected site. After completing a full thickness flap, the flap was gently elevated. Atraumatic extraction was done using straight periotoms (Hu-Friedy, USA.) and forceps. 
Laser assisted socket preservation procedures done as following: curettage and bone perforation of the extracted socket using Er,Cr:YSGG; hard tissue laser. Stabilization of the blood clot and biostimulation of the socket using LLLT; soft tissue diode laser with 0.8 wate for 30 second ${ }^{(14)}$.

The socket was curetted according to the method used in each group: In Group 1(GP1), curettage done using bone curette and saline solution. In GP2 and GP3, curettage of the extracted socket and bone perforation done using Er,Cr:YSGG (Waterlase Biolase ${ }^{\circledR}$, Biolase, Inc., San Clemente, California, USA) of $2.78 \mu \mathrm{m}$ wavelength .

\section{Platelet Rich Fibrin Preparation}

The following is how the PRF was prepared ${ }^{(15)}$ : $10 \mathrm{~mL}$ autologous blood taken from the patient without the use of an anticoagulant. The blood was immediately centrifuged for 10 minutes at 3000 revolutions/min at room temperature after being moved into a $10-\mathrm{mL}$ glass tube. In the middle of the tube, just between the red corpuscles at the bottom and the cellular plasma at the top, a fibrin clot was formed. The PRF clot was removed from the tube with sterile tweezers after centrifugation, and the RBC base was separated with scissors. By compressing the clots with sterile gauze, the serum was drained from them.

In GP1 and GP3, xenograft and PRF was applied to the extracted socket. In GP2, PRF membranes only applied to the extracted socket. In GP2 and GP3, stabilization of blood clot and biostimulation of the socket were done using LLLT diode laser (Picasso Dental Diode Laser, AMD laser). Resorbable suture with figure 8 was used to close the wound. Suture was removed 7-10 days postoperatively.

Patient was instructed postoperatively to use the following medication:Antibiotic(amoxicillinClavulanic acid) orally :1gm every 12 hours for 7 days + metronidazole orally tab every 12 for 7 day. Anti-inflammatory (diclofen potassium) $50 \mathrm{mg}$ tab every 8 hours . Anti-edematous (chymotrypsin- trypsin) 1tablet 3times daily for 5 days. Patient recalled for the follow up at 3 and 6 months postoperatively.

\section{Clinical evaluation}

- Patients were evaluated clinically at baseline (BL), 3 months (3M) and 6 months (6M) post operatively.

- The width of socket was measured using bone caliber from mid of mesial to the mid of distal sides of socket (W1) and from mid of buccal to the mid of lingual sides of socket (W2) fig (1).

- Clinically vertical height was measured at six points: Mesio buccal line angle (L1), Mid buccal (L2), Disto buccal line angle (L3), Mesio lingual line (L4), Mid lingual (L5), Disto lingual line angle (L6).

\section{Radiographic evaluation}

Six months postoperatively, bone density recorded by selecting fixed point locates inside the pre extracted socket using CBCT.

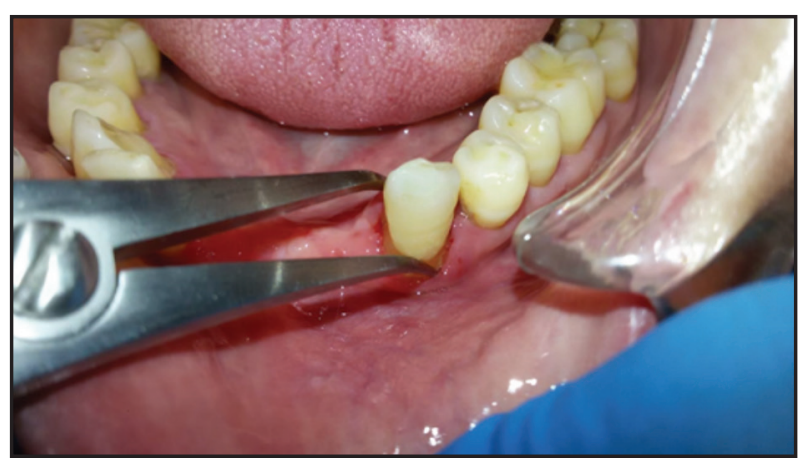

Figure (1) Using bone caliber to measure preoperative ridge width

\section{RESULTS}

The two-way repeated measures ANOVA test was used to compare the groups as well as to study the changes within and group for parametric data. The percentages of positive cells in the three groups were compared using a one-way ANOVA test. When the ANOVA test was important, Bonferroni's 
post-hoc test was used for pair-wise comparisons. The Kruskal-Wallis test was used to compare the three groups for non-parametric results. Friedman's test and the Wilcoxon signed-rank test were used to examine the changes in each category over time. When the Kruskal-Wallis or Friedman's tests were important, Dunn's test was used for pair-wise comparisons.

\section{Clinical evaluation results:}

Ridge width: for W1 ridge width there was no statistically significant difference between the three groups at baseline, three months, or six months. Although there was no statistically significant difference in mean ridge width between Groups II and III for W2, both showed statistically significantly higher mean ridge width than Group I, which had the statistically significantly lowest mean ridge width Table 1.

As regards vertical height L1: there was no statistically significant difference between Groups I and II; both had significantly shorter mean ridge lengths than Group III, which had significantly longer mean ridge lengths. After three and six months, there was no statistically significant difference between the three groups for L2, L3, L4, L5 and L6 Table 2.

\section{Radiographic evaluation results:}

In terms of bone density, there was no statistically significant difference between the three groups. Group II had a higher mean value of bone density as show in Table 3

Table (1) Effects of two-way repeated steps and descriptive statistics the ANOVA test was used to compare the ridge widths in the three groups.

\begin{tabular}{|c|c|c|c|c|c|c|c|c|c|}
\hline \multirow{2}{*}{ Site } & \multirow{2}{*}{ Time } & \multicolumn{2}{|c|}{ GP I } & \multicolumn{2}{|c|}{ GP II } & \multicolumn{2}{|c|}{ GP III } & \multirow{2}{*}{$P$-value } & \multirow{2}{*}{$\begin{array}{c}\text { Effect size } \\
\text { (Partial Eta } \\
\text { Squared) }\end{array}$} \\
\hline & & Mean & SD & Mean & SD & Mean & SD & & \\
\hline \multirow{3}{*}{ Mid-Buccal to Mid-Lingual } & Base line & 5.2 & 1.11 & 5.45 & 1.21 & 5.95 & 1.64 & 0.455 & 0.057 \\
\hline & 3 months & $5.75^{\mathrm{B}}$ & 0.95 & $6.15^{\text {в }}$ & 0.94 & $6.95^{\mathrm{A}}$ & 1.17 & $0.043^{*}$ & 0.208 \\
\hline & 6 months & $5.8^{\text {в }}$ & 0.89 & $7^{\mathrm{A}}$ & 0.94 & $7.05^{\mathrm{A}}$ & 0.98 & $0.009^{*}$ & 0.296 \\
\hline \multirow{3}{*}{ Mid-Mesial to Mid-Distal } & Base line & 5.75 & 1.84 & 5.1 & 1.73 & 6.3 & 1.93 & 0.357 & 0.073 \\
\hline & 3 months & 5.7 & 1.86 & 5.1 & 1.73 & 6.4 & 1.88 & 0.297 & 0.086 \\
\hline & 6 months & 5.65 & 1.94 & 5.1 & 1.73 & 6.45 & 1.88 & 0.278 & 0.09 \\
\hline
\end{tabular}

*: $P \leq 0.05$ indicates a statistically significant difference between groups, and different superscripts in the same row indicate a statistically significant difference between groups according to Bonferroni's test. 
Table (2) Effects of two-way repeated steps and descriptive statistics the ANOVA test was used to compare the ridge lengths in the three groups.

\begin{tabular}{|c|c|c|c|c|c|c|c|c|c|}
\hline \multirow{2}{*}{ Site } & \multirow{2}{*}{ Time } & \multicolumn{2}{|c|}{ GP I } & \multicolumn{2}{|c|}{ GP II } & \multicolumn{2}{|c|}{ GP III } & \multirow{2}{*}{$P$-value } & \multirow{2}{*}{$\begin{array}{c}\text { Effect size } \\
\text { (Partial Eta } \\
\text { Squared) }\end{array}$} \\
\hline & & Mean & SD & Mean & SD & Mean & SD & & \\
\hline \multirow{3}{*}{ Mesio-buccal line angle } & Base line & 8.35 & 2.66 & 8.2 & 1.75 & 9 & 2.52 & 0.722 & 0.024 \\
\hline & 3 months & $8.5^{\text {в }}$ & 1.99 & $9.5^{\text {в }}$ & 1.78 & $11.4^{\mathrm{A}}$ & 1.94 & $0.007 *$ & 0.307 \\
\hline & 6 months & $8.6^{\mathrm{B}}$ & 2.08 & $9.95^{\text {в }}$ & 1.74 & $12.3^{\mathrm{A}}$ & 1.77 & $0.001 *$ & 0.427 \\
\hline \multirow{3}{*}{ Mid-Buccal } & Base line & 7.5 & 2.92 & 6.5 & 1.78 & 6.45 & 1.85 & 0.508 & 0.049 \\
\hline & 3 months & 7.8 & 2.47 & 7.1 & 1.65 & 8.6 & 2.23 & 0.705 & 0.026 \\
\hline & 6 months & 8 & 2.51 & 8.7 & 1.64 & 9.45 & 1.54 & 0.265 & 0.094 \\
\hline \multirow{3}{*}{ Disto-buccal line angle } & Base line & 8.9 & 2.41 & 8.05 & 2.09 & 7.65 & 2.15 & 0.560 & 0.042 \\
\hline & 3 months & 9 & 3.09 & 9.35 & 1.9 & 9.7 & 2.15 & 0.815 & 0.015 \\
\hline & 6 months & 9.2 & 3.07 & 9.7 & 1.75 & 10.65 & 1.9 & 0.378 & 0.07 \\
\hline \multirow{3}{*}{ Mesio-lingual line angle } & Base line & 12.35 & 3.66 & 10.65 & 2.53 & 11.4 & 2.76 & 0.551 & 0.043 \\
\hline & 3 months & 12.6 & 3.38 & 11.75 & 2.6 & 13.4 & 3.92 & 0.615 & 0.035 \\
\hline & 6 months & 12.75 & 4.6 & 12.1 & 2.4 & 14.1 & 4.05 & 0.496 & 0.051 \\
\hline \multirow{3}{*}{ Mid-lingual } & Base line & $13.85^{\mathrm{A}}$ & 4.12 & $9.17^{\text {в }}$ & 3.17 & $11.5^{\mathrm{A}}$ & 3.44 & $0.048^{*}$ & 0.202 \\
\hline & 3 months & 14 & 4.52 & 10.3 & 2.91 & 12.3 & 4.04 & 0.122 & 0.144 \\
\hline & 6 months & 14.1 & 4.5 & 10.9 & 2.76 & 13.35 & 4.01 & 0.167 & 0.124 \\
\hline \multirow{3}{*}{ Disto-lingual line angle } & Base line & 14.45 & 4.87 & 10.2 & 2.02 & 12 & 3.57 & 0.055 & 0.197 \\
\hline & 3 months & 14.85 & 4.01 & 11.35 & 2.16 & 13.65 & 4.37 & 0.112 & 0.15 \\
\hline & 6 months & 10.05 & 4.11 & 11.85 & 2.03 & 14.5 & 4.55 & 0.141 & 0.135 \\
\hline
\end{tabular}

*: $P \leq 0.05$ According to Bonferroni's test, different superscripts in the same row indicate statistically significant differences between groups.

Table (3) For comparison of bone density values in the three groups, descriptive statistics and the results of the Kruskal-Wallis test were used.

\begin{tabular}{|c|c|c|c|c|c|c|c|c|c|c|}
\hline \multicolumn{3}{|c|}{ GP I } & \multicolumn{3}{|c|}{ GP II } & \multicolumn{3}{|c|}{ GP III } & \multirow{2}{*}{ P-value } & \multirow{2}{*}{$\begin{array}{c}\text { Effect } \\
\text { size (Eta } \\
\text { Squared) }\end{array}$} \\
\hline Median & Min. & Max. & Median & Min. & Max. & Median & Min. & Max. & & \\
\hline 716.5 & 428 & 1976 & 790.5 & 538 & 1222 & 744 & 418 & 1206 & 0.676 & 0.045 \\
\hline
\end{tabular}

*: Significant at $P \leq 0.05$. 


\section{DISCUSSION}

Extraction of the tooth can be considered the most common procedures that take place in the dental clinic. This extraction is used to remove decayed, damaged, or periodontally infected teeth that cannot be restored. Loss of teeth can lead to many an adverse effect among which is alveolar atrophy. Since bone is usually thinner during the first three months after extraction, the majority of these changes occur in the buccal layer ${ }^{(16)}$.

For preservation of the alveolar materials many grafting materials have been introduced. A clinical decision tree introduced for esthetic zone alveolar ridge preservation as following; if the clinical cases have buccal bone present more than $50 \%$ proposed extraction socket preservation, but if buccal bone loss more than $50 \%$ a guided bone regeneration procedure suggested for those cases. Maintain alveolar ridge profile can occur through maintaining alveolar ridge dimensions (socket preservation) and increasing volume of the ridge (guided bone regeneration) ${ }^{(17)}$.

In the present study, xenograft was used as bone grafting material because xenograft have many advantages as; no need of other surgery of donor site, it has osteoconductivity and biocompatibility, composed of carbonated hydroxyapatite and type I collagen which is similar to autografts in chemical and structural composition and morphological similarity (regarding bone surface, porosity and the potential of being resorbed) ${ }^{(18)}$.

PRF have many advantages as including more bone fill, rapid soft tissue healing, increase bone density, decrease alveolar ridge reduction and more mature bone. There are several growth factors in PRF; PDGF, TGF- $\beta$, IGF, EGF, fibroblast growth factor, and bone morphogenic protein in addition, PRF is sheep, no need for anticoagulant, and because it is from the patient own blood; no rejection occur (19). For those reasons; PRF has been selected to use in the present study.
Generally, laser has many advantages over conventional rotary drills as no or little pain; in which the operator can complete the work with no need for anesthesia, reduction of noise and vibrations. Er,Cr:YSGG has a wavelength of $2.78 \mathrm{~m}$, which is strongly absorbed by water and hydroxyapatite, which is the most abundant component in bone and dentin. Er,Cr:YSGG can also be used for gingivectomy and unerupted tooth exposure.... etc $^{(20)}$. So Er,Cr:YSGG choiced in this study.

We used strict included and excluded criteria in the step of patient selection so as to minimize the variations that could affect in our results. Our patients were medically free to avoid any diseased that may effect on bone healing process or may lead to liability for infections ${ }^{(21)}$. Smoking patients also excluded from our study as smoking has bad effects on bone healing; it adversely effect on functions of host cells hence cause alteration in inflammatory response. It also decreases the blood supply and cause delayed healing ${ }^{(22)}$.

In the present study, straight periotoms used for atraumatic extraction. The atraumatic extraction serve the periodontal ligaments that surrounded the tooth to be extracted then this decrease damage of bone which is the main principle in ridge preservation procedures ${ }^{(23)}$.

The Er,Cr:YSGG laser has one of the highest absorptions in water, ten times that of the $\mathrm{CO}_{2}$ laser, 200 times that of the Ho:YSGG laser, and around 20,000 times that of the Nd:YAG laser. The organic matrix and inorganic calcium salts have the ability to absorb infrared irradiation between $2.9 \mu \mathrm{m}$ and $3.3 \mu \mathrm{m}$, in addition to the water content of the bone tissue ${ }^{(24)}$. Thus, the good results obtained in this study with the Er,Cr:YSGG laser, which included established ablation with no tissue particle waste and minimal signs of necrosis, are understandable.

In that present study, use of xenograft and PRF showed increase in bone fill this results was in compatible with a study concluded that in both clinical and radiographic parameters, the test 
site (PRF and xenograft) showed $2.31 \mathrm{~mm}$ bone fill $(8.7 \%)$ relative to the control site (atraumatic extraction only $)^{(7)}$. Another study reported that there was no statistically significance differenced found in the use of xenograft as a socket preservative material ${ }^{(25)}$.

In concerning bone density there were no statistically significant variations between the three groups, but group 2 had a higher mean bone density. This was consistent with a previous study which claimed that the PRF group had higher bone density and that the difference between the PRF and nonPRF groups was statistically important in bone density values in 3,6 and 9 months intervals ${ }^{(26)}$. Also another study found that PRF placement after extraction procedure improved the bone width, bone height and quality of bone ${ }^{(27)}$.

\section{CONCLUSION}

Combination of laser assisted ridge preservation of both soft and hard tissue laser with PRF and / or xenograft can be successfully used in ridge preservation after tooth extraction.

\section{RECOMMENDATIONS}

Further studies needs to evaluate the effect of using laser alone without PRF neither bone graft in extracted socket.

\section{ACKNOWLEDGMENT}

I would like to express many thanks and deep gratitude to Dr. Khalid Kera for his help in the statistical results of this study and I would like to thank Dr. Kareem El Tabrany for his help in the radiographic measurements of $\mathrm{CBCT}$ in our study.

\section{DECLARATION STATEMENT}

Authors declare no conflict of interest.

\section{FUND RECEIVED}

The study was self-funded by the principal investigator.

\section{REFERENCES}

1. Pier C, Stefano P, Giovan B , Viviana D , Michele B , Antonio L,et al. Reasons for tooth extractions and related risk factors in adult patients: a cohort study. Int J Environ Res. 2020; 17:2575-80.

2. Pedro S, Povilas D, Lukas P, Lorena M , Maria H. Molecular and cellular aspects of socket healing in the absence and presence of graft materials and autologous platelet concentrates: a focused review. J Oral Maxillofac Res. $2019 ; 10: 1-18$.

3. Soekobagiono S, Adrian A, Agus D. RANKL expressions in preservation of surgical tooh extraction treated with Moringa (Moringa oleifera) leaf extract and demineralized freeze-dried bovine bone xenograft. Dent J.2017;50:149-53.

4. Baratam S, Pradipta D, Moumita M, Abdul Q, Kedar $\mathrm{C}$, Shaikh J. Wound healing and bone regeneration in postextraction sockets with and without platelet-rich fibrin. Ann Maxillofac Surg. 2018;8:28-34.

5. Marcos K, Moacyr D, Luciana C, Suzana C, João G. Evaluation of the effect of platelet- rich plasma on alveolar wound healing in rats. Int. J. Morphol. 2017;35:251-8.

6. Gabriella B, Andreas I, Charles A, Nikola A, Georgios E, Nikolaos S. Ridge preservation procedures after tooth extractions: a systematic review. Int J Dent. 2018; 2018:8546568

7. Prathyusha K, Suneetha K, Chinni D, Sruthima N. Effectiveness of naturally derived bovine hydroxyapatite $\left(\right.$ Cerabone $\left.^{\mathrm{TM}}\right)$ combined with platelet-rich fibrin matrix in socket preservation: A randomized controlled clinical trial. J Indian Soc Periodontol. 2019;23:145-51.

8. Eman A, Naglaa K, Halaa H. Evaluation of alveolar ridge preservation using a composite of bioactive glass and platelet rich fibrin alone or combined with melatonin in chronic periodontitis patient. ADJ-for Girls. 2018;5: 429-38

9. Jiayu P, Quifang X, Jingya H, Yun W, Yanqing L, Rong L,et al. Effect of platelet-rich fibrin on alveolar ridge preservation a systematic review. JADA. 2019:150:766-78.

10. Linhua G,Yunxin Z, Rong S. Er,Cr:YSGG laser application for the treatment of periodontal furcation involvements. Photomed Laser Surg. 2017 ;35:92-7

11. Bhagyashree RK, Amit AA,Chetan PR. Effect of low-level laser therapy on wound healing and patients' response after scalpel gingivectomy: A randomized clinical split-mouth study. J Indian Soc Periodontal.2018;22:419-26. 
12. Hector FR. Wenche SB, Erika B. The Use of cone-beam computed tomography in management of patients requiring dental implants: an american academy of periodontology best evidence review. J Periodontol 2017; 88:946-59.

13. Daniel C, Yogalakshmi R, Sarmad P, Sunita H, Darren C, Mark R,et al. Advanced platelet-rich fibrin and freezedried bone allograft for ridge preservation: A randomized controlled clinical trial. J Periodontol. 2018;89:379-87.

14. Sleem SM, Zayet MK, El-Ghareeb TI, Saleh HA. Evaluation of the bio-stimulatory effect of platelet rich fibrin augmented by diode laser compared to platelet rich fibrin alone on dental implant replacing posterior mandibular teeth. Randomized clinical trial: split mouth study. Maced J Med Sci. 2019;7:869-75.

15. Pedro CA, Stephania PS, Felipe EP, María IS, Nicolás CA, Guillaume $S$,et al. Leukocyte and platelet-rich fibrin have same effect as blood clot in the 3-dimensional alveolar ridge preservation. A split-mouth randomized clinical trial. J Oral Maxillofac Surg. 2021;79:575-84.

16. Giorgio S, Marco L, Lorenzo F, Giulia M, Luca L, Dario $\mathrm{DN}$,et al. Post extractive alveolar ridge preservation using L-PRF: clinical and histological evaluation. Case Rep Dent. 2020;2020:5073519.

17. Arturas S, Gintaras J, Albinas G, Ricardas K, Gintaras J. Randomized and controlled clinical trial of bone healing after alveolar ridge preservation using xenografts and allografts versus plasma rich in growth factors. J Oral Implantol. 2020;46:515-25.

18. Patricia D, Miriam L, Julia S, Pío G, Mariana L. Current stage of marine ceramic grafts for 3D bone tissue regeneration. Mar Drugs. $2019 ; 17: 471-7$.

19. Jiayu P, Quifang X, Jingya H, Yun W, Yanqing L, Rong L,et al. Effect of platelet-rich fibrin on alveolar ridge preservation: a systematic review. J Am Dent Assoc. 2019;150:766-78.

20. Reza F , Mohammad M , Nasim C. The esthetic crown lengthening by Er;Cr:YSGG laser: a case series.J Lasers Med Sci. 2018;9:283-7.

21. Amr MR,Hala KA, Shaimaa MM,Ahmed ES.Pure collagen cone versus collagen cone blended with Gentamicin in alveolar ridge preservation following extraction of chronic infected tooth a randomized histological and clinical study. Egyp Dent J. 2020;66:2272-88.

22. Eden A, Kristina Y, Olga G. Impaired wound healing: facts and hypotheses for multi-professional considerations in predictive, preventive and personalised medicine. EPMA J. 2017; 8:23-33

23. Yoginder S, Rajni S. Latest trends in atraumatic extraction of teeth. Inter J Appli Dent Sci.2020;6:361-66.

24. Gyanendra K, Ferah R, Vivek C. Soft tissue applications of Er,Cr:YSGG Laser in Pediatric Dentistry. Int J Clin Pediatr Dent. 2017;10:188-92.

25. Iorio $\mathrm{S} \mathrm{V}$, Ramaglia L, Blasi A, Bucci P, Nuzzolo P, Riccitiello F, et al. Dimensional changes following alveolar ridge preservation in the posterior area using bovinederived xenografts and collagen membrane compared to spontaneous healing: a 6- month randomized controlled clinical trial. Clin Oral Investig. 2020;24:1013-23.

26. Shaaban MA, Fahmy AM, El Khourazaty NS. Effect of the platelate rich fibrin(PRF) on bone density in immediate implant and loading in esthetic zone( a randomized clinical trial). Egyp Dent J. 2021; 67:669-77.

27. Mandeep Sharma, Praveen Akhtar Lone, Rohit Singh, Abdul Waheed and Vinay Pati. Effects of autologous platelet rich fibrin in bone regeneration in post-extraction mandibular sockets. Inter J Appli Dent Sci. 2018; 4: 309-13. 